\title{
Evaluasi Kesesuaian Sistem Penyimpanan Obat, Suplemen, dan Kosmetik Eceran pada Salah Satu Gudang Pedagang Besar Farmasi (PBF) di Jakarta Pusat
}

Magdalena Wahyu Kristanti, ${ }^{*}$, Zelika Mega Ramadhania²

\author{
${ }^{1}$ Program Studi Profesi Apoteker, Fakultas Farmasi, Universitas Padjadjaran, Jatinangor 45363 \\ 2Departemen Biologi Farmasi, Fakultas Farmasi, Universitas Padjadjaran, Jatinangor 45363 \\ *email: magdalena18001@unpad.mail.ac.id \\ (Submit 12/2/2020, Revisi 12/2/2020, Diterima 13/2/2020)
}

\begin{abstract}
Abstrak
Aspek penyimpanan dalam gudang Pedagang Besar Farmasi (PBF) merupakan parameter yang sangat penting dalam suatu rantai distribusi sediaan farmasi. Sistem penyimpanan yang baik dan benar diatur dalam Cara Distribusi Obat yang Baik (CDOB). Beberapa penelitian menunjukkan bahwa gudang yang menerapkan sistem penyimpanan sesuai $\mathrm{CDOB}$ terhindar dari menumpukknya produk kedaluwarsa dan kerugian finansial, sebaliknya gudang yang belum menerapkan CDOB mengalami kerugian fisik sediaan farmasi dan juga kerugian finansial. Hal ini berdampak kepada penurunan produktivitas dari PBF tersebut. Maka dari itu, diperlukan adanya evaluasi sistem penyimpanan pada salah satu gudang PBF di Jakarta Pusat. Penelitian dilaksanakan selama bulan September 2019 menggunakan metode observasional yang bersifat deskriptif dan evaluatif serta metode wawancara. Hasil penelitian mengenai sistem penyimpanan obat, suplemen, dan kosmetik eceran pada salah satu gudang PBF di Jakarta Pusat menunjukkan bahwa sebagian sistem penyimpanan yang digunakan oleh PBF tersebut belum sesuai dengan CDOB.
\end{abstract}

Kata Kunci : Evaluasi, Penyimpanan, Gudang, PBF, CDOB.

\section{Outline}

- Pendahuluan

- Metode

- Hasil dan Pembahasan

- Kesimpulan

- Daftar Pustaka

\section{Pendahuluan}

Sediaan farmasi terdiri dari obat, bahan obat, obat tradisional, dan kosmetika ${ }^{1}$. Sediaan farmasi harus memenuhi kriteria aman, berkualitas, dan bermanfaat pada semua tahapan, termasuk distribusi. Pedagang Besar Farmasi (PBF) merupakan perusahaan yang memiliki izin untuk mengadakan, menyimpan, dan menyalurkan sediaan farmasi dalam jumlah besar ${ }^{2}$. Pengelolaan perbekalan farmasi di PBF dilaksanakan oleh bagian logistik. Agar tercapai tingkat efisiensi dalam pengelolaan perbekalan farmasi, manajemen logistik yang baik sangat diperlukan. 
Dalam pelaksanaannya, salah satu bagian yang penting dalam manajemen logistik adalah fungsi penyimpanan. Tata cara mengenai penyimpanan sediaan farmasi yang baik dan benar diatur dalam Pedoman Teknis Cara Distribusi Obat yang Baik (CDOB). Tujuan dari $\mathrm{CDOB}$ adalah memastikan mutu sediaan farmasi sepanjang jalur distribusi sesuai dengan persyaratan dan tujuan penggunaannya ${ }^{3}$. Penyimpanan termasuk kedalam salah satu dari sembilan aspek CDOB yaitu Operasional.

Fungsi penyimpanan dalam gudang merupakan suatu parameter kritis dalam rantai pasok yang akan menentukan kelancaran alur pendistribusian dari pemasok ke pelanggan ${ }^{4}$. Pelaksanaan penyimpanan yang sesuai akan menghindarkan dari kesalahan, penggunaan secara tidak bertanggung jawab, menjaga kelangsungan persediaan, serta memudahkan pencarian dan pengawasan.

Penelitian yang dilakukan oleh Tiasari menyebutkan bahwa dari 48 PBF yang terdaftar di Dinas Kesehatan Provinsi DIY, diantaranya 12,7\% PBF tidak memenuhi Standar Prosedur Operasional (SPO), 12,5\% PBF tidak menerapkan sistem (First Expired First Out) FEFO, 11\% PBF tidak memiliki alat pengatur kelembapan, dan 16,3\% PBF tidak memenuhi dokumentasi. Hal ini menunjukkan bahwa sebagian PBF belum menerapkan $\mathrm{CDOB}^{5}$. Mellen dan Pudjirahardjo meneliti bahwa penerapan CDOB yang buruk seperti belum dipenuhinya syarat sarana dan prasarana menyebabkan terjadinya kerusakan obat di gudang. Sebaliknya, penerapan CDOB seperti prinsip First Expired First Out (FEFO) dapat mencegah terjadinya obat rusak akibat kedaluwarsa ${ }^{6}$. Penelitian Septiarini menunjukkan bahwa, rumah sakit yang menerapkan CDOB memenuhi persyaratan jumlah obat kedaluwarsa dan jumlah obat dead stock yang dipersyaratkan oleh WHO. Obat kedaluwarsa merupakan indikasi adanya permasalahan penyimpanan ${ }^{7}$. Syahreni dan Bondan meneliti 31 apotek di Kota Yogyakarta. Penyebab terbesar kerusakan obat adalah kesalahan pada proses penyimpanan $(54,84 \%)$ sedangkan penyebab terbesar obat kedaluwarsa adalah tidak diterapkannya prinsip FEFO (48,39\%). Hal ini menimbulkan kerugian secara finansial karena obat tidak dapat dipakai lagi dan memerlukan biaya untuk pemusnahan ${ }^{8}$. Manajemen logistik yang baik akan meningkatkan produktivitas PBF sehingga dapat mengurangai biaya pemusnahan, mengurangi jumlah item yang kedaluwarsa, meningkatkan ketepatan waktu, dan meningkatkan kepuasan pelanggan? .

Oleh karena pentingnya penerapan $\mathrm{CDOB}$ pada fasilitas distribusi, maka perlu dilakukan evaluasi kesesuaian sistem penyimpanan sediaan farmasi pada salah satu gudang PBF di Jakarta Pusat dalam rangka memastikan penyimpanan sesuai CDOB.

\section{Metode}

Penelitian dilaksanakan selama bulan September 2019 di salah satu PBF di Jakarta Pusat. Penelitian dilakukan menggunakan metode observasional yang bersifat deskriptif dan evaluatif dimana dilakukan pemantauan dan evaluasi pada kegiatan yang sedang berjalan. Wawancara kepada penanggung jawab gudang dilakukan untuk mengonfirmasi sistem yang diobservasi. 


\section{Hasil dan Pembahasan}

Penelitian dilakukan pada gudang obat, suplemen, dan kosmetik eceran salah satu PBF di Jakarta Pusat. Bangunan dan peralatan yang terdapat pada PBF tersebut merupakan bangunan permanen yang sudah memenuhi syarat CDOB sehingga dapat memberikan jaminan keamanan dan kualitas pada obat, suplemen, dan kosmetik yang disimpan. Ruangan yang terdapat pada PBF tersebut sudah diatur dan dipisahkan sedemikian rupa sesuai $C D O B$, sehingga area untuk menyimpan, menerima, dan mengirim sudah terpisah sebagaimana seharusnya. Bangunan dan fasilitas sudah memberikan perlindungan terhadap serangga ${ }^{3}$. Selama observasi dan berdasarkan keterangan dari penanggung jawab gudang, belum pernah terlihat adanya serangga atau hewan yang masuk dan merusak kualitas dari obat, suplemen, dan kosmetik yang disimpan.

Suhu pada gudang PBF tersebut sudah disesuaikan dengan kebutuhan penyimpanan masing-masing obat, suplemen, dan kosmetik. Bangunan dilengkapi dengan pengatur suhu ruangan beserta termometer. Penyimpanan obat, suplemen, dan kosmetik yang memerlukan suhu khusus sudah dilakukan di lemari pendingin atau ruangan khusus seperti yang dipersyaratkan. Lemari pendingin sudah dilengkapi dengan sistem pemantauan suhu berupa termometer dan alarm untuk mendeteksi jika terjadi penyimpangan suhu.

Terdapat beberapa tipe aturan penyimpanan yaitu penyimpanan berbasis volume (pengelompokan berdasarkan permintaan dan penetapan jarak lokasi ke area pengiriman), penyimpanan berbasis acak (penempatan dimanapun tanpa strategi apapun), dan penyimpanan berbasis kelas (pengelompokan menjadi beberapa kategori berdasarkan kesamaan, karakteristik, atau parameter yang lain). Ilustrasi tipe penyimpanan dapat dilihat pada Gambar $1^{11}$. Pedagang Besar Farmasi di Jakarta Pusat yang diteliti menerapkan tipe penyimpanan berbasis kelas. Berdasarkan observasi dan wawancara kepada penanggung jawab gudang mengenai sistem penyimpanan yang digunakan, produk diklasifikasikan menjadi beberapa kategori yaitu jenis prinsipal, bentuk sediaan, tujuan penggunaan, dan suhu penyimpanan. Sistem yang digunakan bertujuan untuk mendukung kelancaran proses distribusi kepada pelanggan. Namun berdasarkan observasi, sistem yang digunakan belum sepenuhnya diterapkan dengan baik sehingga berakibat pada terhambatnya proses distribusi dan menyebabkan adanya beberapa produk yang mengalami kebocoran, mendekati tanggal kedaluwarsa, hingga produk yang sudah kedaluwarsa.

Berikut ini merupakan aturan yang terdapat pada CDOB beserta evaluasi di gudang obat, suplemen, dan kosmetik eceran pada salah satu PBF di Jakarta Pusat:

1. Penyimpanan obat dan/atau bahan obat harus terpisah dari produk selain obat dan/atau bahan obat. Produk harus terlindung dari cahaya matahari langsung, suhu, dan kelembapan yang ekstrem. Terpisah yang dimaksud adalah harus berbeda rak/ruang/lemari/ruangan dan diberi label sesuai dengan analisis risiko, misalnya risiko kontaminasi ${ }^{3,12,13}$. 


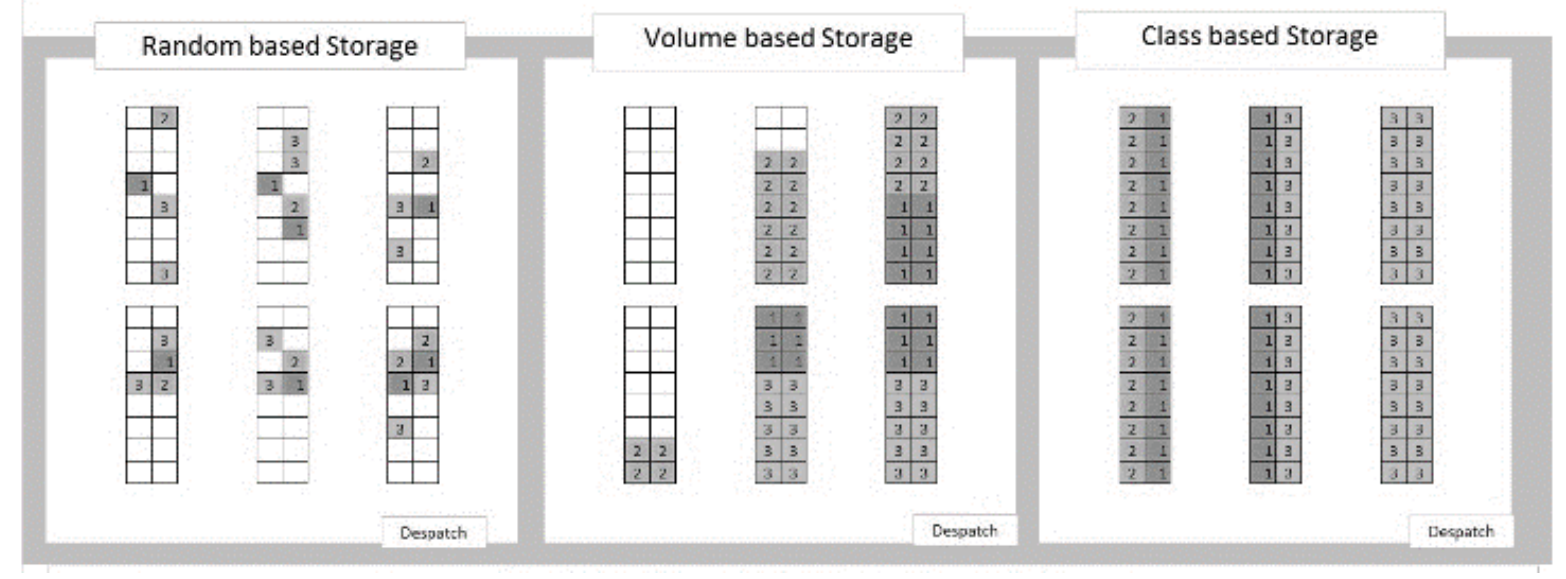

Gambar 1. Aturan Tipe Penyimpanan

Obat, suplemen, dan kosmetik pada PBF yang diteliti sudah disimpan pada tempat yang terlindung dari cahaya matahari langsung. Suhu ruangan dan tempat penyimpanan sudah diatur sedemikian rupa sehingga sudah memenuhi persyaratan. Kelembapan dipantau dengan alat pengukur kelembapan dan dicek secara berkala. Namun, masih terdapat produk selain obat, suplemen, dan kosmetik yang tersimpan pada rak obat, suplemen, dan kosmetik. Terdapat beberapa alat kesehatan yang terselip pada rak obat, suplemen, dan kosmetik. Pelabelan yang digunakan pada rak juga belum sesuai dengan penempatan obat, suplemen, dan kosmetik. Terlebih lagi, prinsip penyusunan secara alfabetis pada obat, suplemen, dan kosmetik belum diterapkan sepenuhnya dan beberapa produk masih tersusun secara acak. Perlu dilakukan pengorganisasian secara alfabetis dari $A-Z$ dalam rangka meningkatkan efisiensi kegiatan operasional dan menghindari kesalahan pengambilan obat, suplemen, dan kosmetik ${ }^{13}$.

2. Penanganan dan penyimpanan obat dan/atau bahan obat harus dilakukan dengan sesuai untuk mencegah tumpahan, kerusakan, kontaminasi, dan campur baur. Produk tidak boleh langsung bersentuhan langsung dengan lantai dan diletakkan langsung di lantai, sehingga produk harus diletakkan di atas palet atau rak $(3,12,13)$. Penyimpanan obat, suplemen, dan kosmetik di PBF yang diteliti sudah dilakukan pada rak-rak besi yang tidak bersentuhan langsung dengan lantai. Namun, terdapat campur baur antara bentuk sediaan satu dengan bentuk sediaan lain dan antara prinsipal yang satu dengan prinsipal yang lain. Ditemukan beberapa produk sediaan tablet oral padat dan oral cair (sirup) pada rak penyimpanan produk injeksi. Ditemukan sediaan botol infus pada rak sediaan oral cair. Ditemukan tablet vaginal pada rak penyimpanan tablet oral dan bedak pada rak obat dalam. Penemuan yang lain adalah produk dari prinsipal selain "A" diletakkan pada rak produk dari prinsipal "A". Campur baur mengakibatkan potensi kesalahan pengambilan produk yang mempunyai kemungkinan membahayakan pelanggan sehingga pelanggan menjadi tidak puas. Selain itu, campur baur dapat berpotensi menyebabkan kontaminasi jika ada tumpahan. 
3. Harus dipertimbangkan ketersediaan alat penyimpanan obat dan/atau bahan obat seperti rak, lemari, lemari pendingin, dan lemari beku dalam penataan dan identifikasi tempat penyimpanan obat dan/atau bahan obat. Dipertimbangkan juga jumlah jenis obat dan/atau bahan obat per kelompok tipe penyimpanan dan luas lorong antar rak sehingga dapat digunakan sebagai tempat lewat palet tangan atau alat pengambil yang lain $3,12,13$. Penyimpanan pada PBF yang diteliti sudah menggunakan rak, lemari, lemari pendingin, dan peralatan lainnya yang telah memenuhi syarat. Obat, suplemen, dan kosmetik yang memerlukan suhu penyimpanan rendah ditempatkan di ruangan bersuhu sejuk ataupun lemari pendingin. Namun, pemanfaatan rak dan penempatan kategori obat, suplemen, dan kosmetik belum dilakukan secara optimal sehingga terdapat rak yang isinya terlalu penuh namun terdapat rak yang masih kosong/longgar. Lorong pada PBF tersebut dapat dilewati palet tangan atau alat pengambil yang lainnya sehingga telah memenuhi persyaratan.

4. Kelompok tiap jenis produk harus terpisah dengan jelas dan disimpan secara rapi/teratur untuk mencegah resiko tercampur dan pencemaran. Penatan harus ditata sedemikian rupa sehingga memudahkan pemeriksaan, pemeliharaan dan pengambilannya. Diusahakan diberi jarak antara tiap urutan sehingga memungkinkan adanya aliran udara ${ }^{3,12,13}$. Penemuan pada PBF yang diteliti menunjukkan bahwa klasifikasi penyimpanan obat, suplemen, dan kosmetik eceran belum jelas. Obat, suplemen, dan kosmetik dipisahkan menjadi dua kategori besar yaitu produk dari prinsipal "A" dan produk dari prinsipal selain "A", kemudian produk dari prinsipal selain "A" dikategorikan lagi menjadi beberapa kategori berdasarkan masing-masing prinsipal. Namun sistem klasifikasi ini baru dilakukan pada sediaan oral padat saja, sedangkan untuk sediaan lain selain oral padat belum diterapkan sistem klasifikasi yang serupa. Hal ini mengakibatkan terhambatnya proses pengambilan pesanan karena klasifikasi produk yang tidak teratur. Selain itu, belum terdapat sistem pemisahan untuk obat, suplemen, dan kosmetik yang bersifat LASA (Look Alike Sound Alike) seperti Simvastatin $10 \mathrm{mg}$ dan Simvastatin $20 \mathrm{mg}$ sehingga berpotensi terjadi kesalahan pengambilan kekuatan obat.

5. Penempatan produk dialokasikan sesuai dengan karakteristiknya. Produk yang berat, kemasan botol, dan cairan diletakkan dibawah. Produk-produk yang kecil, mudah pecah (injeksi/vial) diletakkan semudah mungkin untuk pengambilannya. Hendaknya dibuat daftar produk sesuai dengan denah yang dibuat sehingga mempercepat proses pencarian dan penelusuran ${ }^{3,12}$. Alokasi penempatan produk pada PBF yang diteliti sudah sesuai dengan persyaratan. Obat, suplemen, dan kosmetik yang berat, botol cairan yang berukuran besar dan bervolume banyak seperti infus, dan produk yang berat lainnya sudah ditempatkan pada rak bagian bawah. Produk injeksi seperti ampul atau vial diletakkan pada rak yang tidak terlalu tinggi sehingga memudahkan pengambilan dan meminimalisir risiko jatuh dan pecah. Sudah dibuat daftar produk pada masing-masing rak, namun jarang dilakukan pembaharuan pada daftar produk sehingga daftar tersebut menjadi tidak dapat digunakan. 
6. Hendaknya diterapkan sistem FEFO (First Expired First Out) sehingga produk yang diambil memiliki masa simpan yang cukup sebelum kedaluwarsa. Hendaknya diambil langkah yang sedemikian rupa untuk memastikan perputaran persediaan sesuai dengan prinsip $\mathrm{FEFO}^{3,12,13}$. Prinsip FEFO pada PBF yang diteliti belum sepenuhnya diterapkan. Beberapa obat, suplemen, dan kosmetik yang sama terletak terpisah/terpencar di dua rak yang berbeda. Akibatnya, prinsip FEFO dalam pengambilan barang menjadi tidak terpenuhi karna produk yang diambil menjadi tidak sesuai yang seharusnya. Ketidaksesuaian obat, suplemen, dan kosmetik yang diambil berpotensi mengakibatkan menumpuknya produk yang mendekati kedaluwarsa atau bahkan sudah kedaluwarsa.

7. Penyimpanan produk yang diterima disesuaikan dengan persyaratan yang dituntut untuk masing-masing produk. Hendaknya diusahakan agar produk yang baru diterima dengan masa kedaluwarsa yang lebih panjang ditempatkan di belakang produk yang kedaluwarsanya lebih pendek. Demikian pula dengan produk yang baru diterima, ditempatkan di belakang persediaan yang lama sehingga penyaluran produk dapat dilakukan atas dasar prinsip pertama masuk dengan kadaluarsa yang lebih pendek adalah yang pertama keluar ${ }^{3,12}$. Prinsip ini sudah diterapkan pada PBF yang diteliti. Namun, karena terdapat beberapa obat, suplemen, dan kosmetik yang sama tersimpan terpisah pada dua tempat yang berbeda, prinsip penempatan sesuai yang dipersyaratkan menjadi tidak berjalan sesuai aturan.

\section{Kesimpulan}

Sistem penyimpanan obat, suplemen, dan kosmetik eceran pada salah satu gudang PBF di Jakarta Pusat sudah memenuhi syarat CDOB pada aspek bangunan, peralatan, dan suhu. Namun masih terdapat penyimpangan pada sistem penyimpanan tersebut, antara lain klasifikasi kategori belum jelas, pelabelan belum jelas, prinsip alfabetis belum berjalan dengan tertib, penempatan yang belum sesuai, adanya campur baur, pemanfaatan rak belum optimal, mekanisme pemisahan produk LASA belum diterapkan, dan prinsip FEFO belum berjalan sepenuhnya. Hal ini akan berdampak pada kelancaran proses distribusi dan berpotensi menimbulkan penurunan kualitas distribusi serta produktivitas organisasi. Hendaknya dilakukan langkah-langkah atau perbaikan pada sistem penyimpanan obat, suplemen, dan kosmetik eceran di PBF tersebut.

\section{Daftar Pustaka}

1. PP RI. Pekerjaan Kefarmasian. Jakarta: Peraturan Pemerintah Republik Indonesia; 2009.

2. MENKES RI. Pedagang Besar Farmasi. Jakarta: Menteri Kesehatan Republik Indonesia; 2011.

3. BPOM RI. Pedoman Teknis Cara Distribusi Obat yang Baik. Jakarta: Badan Pengawas Obat dan Makanan Republik Indonesia; 2019. 
4. Ramaa, A., Subramanya, KN., Rangaswamy, TM. Impact of Warehouse Management System in a Supply Chain. IJCA. 2012; 54 (1): 14-20.

5. Tiasari, N. Evaluasi Pelaksanaan Cara Distribusi Obat yang Baik pada Pedagang Besar Farmasi di Provinsi Daerah Istimewa Yogyakarta Tahun 2016. Yogyakarta: Universitas Sanata Dharma; 2016.

6. Mellen, RC., Pudjirahardjo, WJ. Faktor Penyebab dan Kerugian Akibat Stockout dan Stagnant Obat di Unit Logistik RSU Haji Surabaya. JAKI. 2013; 1 (1): 99-107.

7. Septiarini, Akabar, DO., Satrio, WR. Evaluasi Manajemen Penyimpanan Obat di Gudang Farmasi Rumah Sakit Daerah Umum Idaman Banjarbaru. Repository STIKES Borneo Lestari; 2017.

8. Syahreni, D., Bondan, A. Gambaran Pengelolaan Obat Rusak dan Kedaluwarsa di Apotek Kota Yogyakarta. Yogyakarta: Universitas Gadjah Mada; 2017.

9. Mutai, C., Moronge, M. Influence of Warehouse Management on Organizational Productivity in State Corporations in Kenya: A Case of Kenya Electricity Generating Company Limited. Strateg. j. bus. change manag. 2017; 4 (2): 588-605.

10. Juliana, H., Handayani, NU. Peningkatan Kapasitas Gudang dengan Perancangan Layout menggunakan Metode Class-Based Storage. JTI. 2016; 11 (2): 113-122.

11. Mickleson, G., Thai VV., Halim, Z. The Influence of Responsibility Shift on Warehousing Performance: The Case of Australia. AJSL. 2019; 35 (1): 3-12.

12. BPOM RI. Petunjuk Pelaksanaan Cara Distribusi Obat yang Baik. Jakarta: Badan Pengawas Obat dan Makanan Republik Indonesia; 2015.

13. WHO. Design and Procurement of Storage Facilities - Annex 9: Model guidance for the storage and transport of time and temperature-sensitive pharmaceutical products. TRS. 2011; 961. 